\title{
LA IRONÍA SOCRÁTICA COMO ARTE DE VIVIR*
}

\author{
Vicente RaGa ROSALENY
}

\begin{abstract}
RESUMEN: Parece que la ironía no podría reducirse a un concepto único, sin embargo, lo que sucede con ésta noción es que acogería una pluralidad de sentidos, fruto del devenir histórico y social de la palabra, unificados por una doble estructura, la que constituirían su lado semántico y su lado pragmático. Aquel que ha podido caracterizar mejor ambos lados de la ironía en su vida es Sócrates, por eso, al hilo de un moderno retorno a la "cuestión socrática", se trataría de desarrollar ambas perspectivas y descubrir la contribución de Sócrates a cada una de ellas. La tesis de este artículo es que, frente a las lecturas contemporáneas principales, que giran en torno a una interpretación semántica de la ironía socrática, en este autor estarían presentes los dos lados, pero de manera principal el pragmático, esto es, la comprensión de la ironía como forma de vida.
\end{abstract}

Arístipo sólo defendía el cuerpo, como si no tuviéramos alma; Zenón sólo se ocupaba del alma, como si no tuviéramos cuerpo. Ambos erróneamente. Pitágoras, según dicen, siguió una filosofía enteramente contemplativa, Sócrates, una toda de costumbres y de actos; Platón halló el término medio entre los dos. Más eso lo dicen por decir y la verdadera medida se halla en Sócrates, y Platón es harto más socrático que pitagórico, y le va mejor. (...)

* Departament de Metafísica y Teoria del Coneixement. Universitat de València. Phrónesisanalytic philosophy group. Becario de investigación FPU del Ministerio de Educación y Ciencia. Este trabajo ha sido llevado a cabo dentro del proyecto de investigación "Creencia, motivación y verdad" (BFF2003-08335-C03-01). 
Nuestra obra de arte, grande y gloriosa, es vivir convenientemente. ${ }^{1}$

La eironeía, dissimulatio, simulatio o ironía se dice de muchas maneras, esto es, parece que no sería posible reducir sus notas a un concepto único ${ }^{2}$. No se trataría tan sólo de una dificultad empírica, de una cuestión que pudiera resolverse en el curso del tiempo. Paradójicamente, parecería decírsenos, una palabra cuya historia habría consistido en un constante adherirse de acotaciones, de clasificaciones y definiciones tópicas, escaparía siempre, por una ambigüedad radical (Nehamas), por una distancia constitutiva (de Man), de cualquier intento de definición. Definir la ironía, como indicarla mediante algún signo gráfico ostensivo (Alcanter de Brahm), sería matarla.

Sin embargo, como indica el filósofo de la historia Koselleck en su libro Futuro pasado, siguiendo explícitamente a Nietzsche, los conceptos, frente a las palabras, serían necesariamente polívocos y, por ello mismo, indefinibles, en la medida en que resumirían una historia, la suya, que quedaría incorporada a su bagaje semiótico ${ }^{3}$. Pues bien, el concepto de «ironía» acogería por una parte una pluralidad de sentidos, fruto del devenir histórico y social de la palabra, pero, por otra parte, no serían simplemente aires de familia lo que uniría a esos diversos sentidos de la palabra ${ }^{4}$. Sino que, como sucedía en la genealogía del concepto de "pena", en el pasaje de La genealogía de la moral del que Koselleck extrae su cita de Nietzsche, el concepto presentaría una doble estructura, una articulación entre la proteica dimensión histórico-social y la duradera reflexión sobre el concepto sintético 5 .

Con una arquitectura análoga a la del famoso verso de Hölderlin: «allí donde crece el peligro, crece también lo que nos salva», el concepto de «ironía» presentaría, junto con la plétora de sentidos a la que aludo, una duplicidad, una doble caracterización surgida de la reflexión sobre esa síntesis indefinible. Si ten-

1 Montaigne, 1987, pp. 391-392.

2 Tal como lo postula Paul de Man en su, por otro lado irónico ya desde el título, texto $E l$ concepto de ironia (de Man, 1996, p. 1).

${ }_{3}$ "Todos los conceptos en los que se resume semióticamente un proceso completo se escapan a la definición; sólo es definible aquello que no tiene historia (Nietzsche)" (Koselleck, 1993, p. 117, las cursivas son del autor).

"Véase para la noción de «aires de familia» los $\$ \$ 66-67$ de Wittgenstein, 1997, pp. 97-98.

5 Véase el $\$ 13$ del segundo tratado de Nietzsche, 1997, p. 103. 
tativamente llamo «semántica» a la primera de esas caracterizaciones y "pragmática" a la segunda, cabría decir que el peligro de la ironía, su lado más negativo (así como los intentos de anularla), vendrían dados por una concepción semántica del lenguaje, ligada a una epistemología y una praxis concretas. Por otro lado, la cara más positiva de la ironía, la salvación de este peligro, surgiría de una noción pragmática que, sin embargo, no dejaría completamente de lado la ambigüedad y el riesgo de la concepción semántica, sino que mantendría irresuelta y presente la tensión entre ambos polos.

Frente a una idea del lenguaje como mero sistema de signos, al estilo del que manejan en su reflexión sobre la ironía de Man, Lang o, en otro contexto, al tratar de la différance, Derrida, la noción de lenguaje que subyacería a la ironía pragmática sería una cercana al todo de expresiones y actividades que constituye una forma de vida ${ }^{6}$. A la primera podría ligarse una noción de sentido en términos de, por ejemplo, una definición ostensiva ${ }^{7}$. Frente a ella se presentaría una nueva alternativa pragmática de corte wittgeinsteniano, vinculada a una cierta normatividad, al seguir una regla. Es decir, una en que el sentido de las expresiones lingüísticas vendría dado por su uso, en tanto que regido por reglas que permitirían decidir qué es lo que cuenta como "actuar de la misma manera» y que a la vez sería un procedimiento necesariamente social ${ }^{8}$.

Así pues, en este artículo daré cuenta a un tiempo de ambos lados de la ironía siguiendo a aquel que mejor ha podido caracterizarlos en su vida, mostrando al mismo tiempo la necesidad vital de este concepto, Sócrates. Y así, al hilo de un moderno retorno a la ya añeja "cuestión socrática», seguiré los rasgos históricamente centrales de la ironía semántica, cuyas dos caracterizaciones principales han imperado a lo largo de la historia del concepto de "ironía". La primera sería la comprensión antifrástica de la ironía, mecanismo retórico simple que

${ }^{6}$ Wittgenstein, 1997, $\$ \$ 7,19$.

7 Una especie de acto bautismal por el que una palabra quedaría asociada a un objeto extralingüístico, convirtiéndose éste en su significado: «Una parte importante del adiestramiento consistirá en que el maestro señale hacia los objetos, que dirija la atención del niño hacia ellos y al hacerlo profiera una palabra: por ejemplo, la palabra 'losa', al mostrar esta forma (a esto (...) quiero llamarlo 'enseñanza ostensiva de las palabras'). (...) Alguien podría decir que esta enseñanza ostensiva de las palabras establece una unión asociativa entre la palabra y la cosa, ¿Pero eso, que quiere decir?» (Wittgenstein, 1997, $\$ 6$, la traducción del catalán es mía).

${ }^{8}$ Marrades, 1998, p. 51. 
suele asociarse a una palabra o período sintáctico breve y que opera mediante la inversión del significado o sentido "real», «intencional", de la frase o palabra, en el significado literal. La segunda sería una nihilista y ambigua concepción de la ironía, que se dispersaría a lo largo de una extensión textual difusa, pudiendo cubrir una obra entera o, alternativamente, toda una vida y en ella el sentido sería siempre otro que el literal, sin llegar a estabilizarse nunca en ningún significado "recto", "auténtico».

Pese a la aparente distancia y oposición entre ambas caracterizaciones, las dos compartirán, una misma base, un mismo supuesto semántico. Ambos tipos de ironía tendrán siempre un carácter referencial, bien refieran a una intención o a un contenido del mundo. Su modelo será el de la relación de correspondencia con una realidad extralingüística, accesible en un caso por vía de la inversión e inalcanzable en el otro, pero siempre como rasgo constituyente del sentido de ese lado de la ironía.

De otra parte, perseguiré a lo largo de mi artículo la otra caracterización de la ironía, mucho más elusiva, a la que apenas se le ha prestado atención en las obras de los principales autores vinculados a la historia del concepto, la vertiente pragmática de la ironía. En este lado de la ironía ésta es concebida como parte de un proceso comunicativo amplio, comprendida en términos meta-referenciales y articulada como mecanismo de corrección de las normas de comunicación en que reposa el sentido de un lenguaje entendido como forma de vida (a la vez que producto de esas mismas normas, de los presupuestos compartidos por la comunidad discursiva).

En ambos casos lo que trataré de elucidar es tanto la contribución de Sócrates a la noción de ironía, en los términos aquí expuestos, como aquellos rasgos irónicos que podrían caracterizarlo más propiamente, ofreciendo una respuesta alternativa a las dos principales que actualmente se disputan la interpretación de su figura y que tienen asimismo como eje central de su lectura del maestro de $\mathrm{Pla}$ tón el concepto de ironía. Estos autores leerían, desde mi perspectiva, la ironía socrática desde su vertiente más semántica, olvidándose de la pragmática y mi propuesta pasará por, sin descuidar ese lado semántico, proponer una lectura decididamente más pragmática que semántica de Sócrates (y así defender mi tesis de que en el antiguo pensador griego tanto están presentes ambas caras de la ironía, como que la suya es la propuesta de un arte de vivir, de una forma de vida). 


\section{II}

El Sócrates de Platón’ es aparentemente uno de los personajes, reales o literarios, más enigmáticos de la antigüedad, o al menos de los más contradictorios de entre los autores que pertenecen al acervo universal. Un tábano para la ciudad de Atenas ${ }^{10}$, que por una misión divina se habría dedicado a interrogar a sus ciudadanos, tratando de despertarles, de persuadirles y reprocharles, de mostrarles que no saben, cuando creían saber ${ }^{11}$. Alguien que considera que una vida sin examen no merece la pena ${ }^{12}$, y que ayudaría sin forzar, en un sentido o en otro, a que cada uno de sus interlocutores llevara a cabo un examen de sí mismo. Un ser, vivo o literario, que consideraría que es peor hacer el mal que recibirlo y que nadie hace daño a sabiendas ${ }^{13}$ (esto es lo que se conoce como el intelectualismo moral de Sócrates, corolario de una supuesta concepción de la areté como conocimiento). Alguien que para muchos, empezando por voces tan relevantes como la de Hegel, ${ }^{14}$ habría sido el padre, o al menos la comadrona, de la ética, así como alguien justo, poseedor de la areté de modo comprehensivo y a lo largo de toda su vida. Ese hombre, al mismo tiempo, declararía explícitamente, y en múltiples ocasiones, ser un ignorante ${ }^{15} \mathrm{y}$, por lo tanto, y siguiendo el argumento antedi-

9 Que, como bien se sabe, no es el único Sócrates que nos ha legado la antigüedad, ya que podría mencionarse al personaje de Aristófanes y reparar también en el de Jenofonte. De hecho, de este último autor tomaré una referencia crucial para nuestros intereses, criticando así, de paso, el olvido al que los exegetas modernos han sometido a esta fuente, tan relevante, por ejemplo, en el periodo anterior.

${ }^{10}$ Apología 30e-31a.

11 Éste es el conocido "método" socrático, el elenchos, consistente en una alternancia de preguntas y respuestas, del que la ironía formaría parte. Como señala Wolf, lo que se propondría el elenchos sería completar la muchedumbre de opiniones que uno tuviera con representaciones éticas de carácter universal, y luego ir gradualmente ordenando ese campo antes desordenado de las opiniones y conceptos, por medio de los cuales uno se refiere a la vida buena (Wolf, 2002, p. 54). Otro elemento relevante, pues, sería acorde con este concepto y con los testimonios disponibles, la conocida mayéutica socrática o arte de la partera, que no buscaría en una doctrina externa, con los peligros del dogmatismo, la enseñanza relativa a la vida buena.

12. Apologia 38a.

13 Acerca de esta cuestión puede consultarse, y sin animo de ser exhaustivo: Prot. 351b-359a; Rep. 1, 351a 5-6; Apologia 29d 2-30a 2; Laques 193d 11-e 6; Lisis 212a 1-7, 223b 4-8 . Sobre este punto volveré con más detalle un poco más adelante.

14 "Sócrates creó e hizo nacer, de este modo, la ética; por eso todas las chácharas éticas y la filosofía popular de la posteridad ven en él su patrono y su santo tutelar" (Hegel, 1955, vol. II, p. 43).

15 Apología 21 a-23c, entre muchos otros pasajes, éste, donde narra la conocida historia del Oráculo de Delfos, es claro respecto a la denegación de conocimiento de Sócrates. 
cho, no podría coherentemente tener areté, ni ser una voz ética, ni en cierto sentido amplio (el propiamente ateniense) política o profética (ya que su misión refutatoria del falso saber de sus conciudadanos sería divina, en tanto que encargada por el Oráculo de Delfos por ser, diría que irónicamente, el hombre más sabio) ${ }^{16}$.

¿Quién es esa paradoja viviente que aguarda en silencio desde el fondo de los siglos? ${ }^{17}$ ¿Qué se oculta detrás de la máscara del sátiro de sonrisa imborrable y gesto lascivo? ${ }^{18}$ ¿Cuál es el sentido de esta ironía que cubre con su capa raída una vida entera? ${ }^{19}$

No resulta fácil responder a estas preguntas, no es sencillo dilucidar si Sócrates, en tanto que figura literaria o real, finge engañosamente su ignorancia (como un eiron aristofánico), si es realmente ignorante, de modo completo o sólo en algún sentido (como en la ironía compleja de Vlastos), o ha de permanecer en la ambigüedad más completa, sin que quepa finalmente decidirse por una u otra opción de entre las posibles (como defenderá Nehamas).

Y no lo es porque, de entrada, del Sócrates que vivió en la Atenas de la Grecia clásica tan sólo llega el silencio, puesto que no dejó escrito nada. Y, además, se asiste a su magisterio, en sus diversos retratos literarios, cuando ya está completamente formado, sin saber de dónde viene, ni cuál es su trayectoria, salvo por referencias breves y, a menudo, contradictorias.

Sin embargo, resulta al mismo tiempo inevitable reflexionar sobre estas preguntas, ya que el estatuto del concepto de ironía, su preponderancia semántica o pragmática, dependerá, de modo relevante, de la respuesta que se dé a la pregunta por la vida socrática: ¿es la suya una ironía vital comprensible como mera inversión? ¿Podríamos escuchar la voz clara del Sócrates moralista tras una dis-

16 Apologia 21b, 22d.

${ }^{7}$ Gorgias 448d; Prot. 334c-e, donde se compara el silencio de Sócrates, su reticencia, su hablar o dialogar breve, su dejar al oponente desarmarse a sí mismo, entrar en contradicción al desarrollar sus presupuestos, con el parloteo sofista, de amplios periodos y cuidados ornamentos.

18 Banquete 216e-218d, 221e, el pasaje de la descripción elogiosa de Sócrates por Alcibíades es de gran relevancia y citaré seguidamente un fragmento.

19 Institutio Oratoria IX, 2. Con lo de raída hago alusión a su aspecto físico, tan poco agraciado, de sátiro como Marsias, que de algún modo ya apunta hacia su condición irónica. 
tancia pedagógica? $\mathrm{O}$ ¿acaso la ambigüedad del silencio impenetrable nos está diciendo siempre otra cosa que lo que parece decirse y por lo tanto no hay un sentido en el que quepa confiar? ¿Es posible que Sócrates muestre una manera o arte de vivir, individual y colectiva, ${ }^{20}$ que requiera revisar la propia forma de vida?

La primera cuestión en la que las discusiones han sido más enconadas de un tiempo a esta parte, sería la de la calidad de testimonio de los primeros diálogos platónicos. Esto es, la de si el Sócrates de los primeros textos platónicos sería un fiel reflejo de la realidad o, por el contrario, tan sólo una creación artística, estilística y filosóficamente relevante, hija de la pluma de Platón. ${ }^{21}$

Y lo cierto es que los argumentos de la facción más débil, los defensores de la veracidad biográfica del testimonio platónico, son relevantes. Basándose en la gran diferencia observable entre la figura socrática de los primeros textos y la de los de un periodo posterior, arguyen que quizá Platón trató de recoger para siempre el legado del posiblemente ágrafo Sócrates. En los subsiguientes textos, sin embargo, Platón habría traicionado la memoria de su mentor, poniendo en su boca las tesis filosóficas propias, tesis que además contravendrían el espíritu de la enseñanza socrática. ${ }^{22}$

Tal lectura, no obstante, pese a ser sugerente, topa con objeciones suficientes como para que finalmente tenga que desestimarla. No sólo es claro que la obra de Platón tiene no tanto pretensiones autobiográficas, cuanto fines filosóficos. Su retrato de Sócrates es un logro estético y ético. Sino que además, contra las pretensiones de ser un reflejo veraz de la figura del hijo de Sofronisco, se levantan las voces de los otros espejos de Sócrates: el aristofánico o el de Jenofonte. Sumándose además, con su multiplicidad y heterogeneidad irreductibles, las múltiples escuelas que, a su muerte, dejó el silencio socrático. ¿Cómo trazar un retrato fiel de un personaje tan elusivo como la ironía a la que encarna y al

${ }^{20}$ O sólo individual, como cuidado de sí, que también esto está en discusión.

${ }^{21}$ La discusión puede seguirse en los textos de Vlastos, 1964 y 1991, así como en la exposición de Peñalver, 2005, por un lado, y por otro, en el texto de Nehamas, 2005. Los primeros estarían a favor de entender los primeros textos de Platón como un espacio donde resonaría el eco de la ipsimissima vox de Sócrates; el segundo rechazaría esa posibilidad, retomando la posición escéptica dominante, aunque con muchos matices.

${ }^{22}$ Peñalver, 2005, pp. 5-6. 
que sus coetáneos entendieron de modo tan dispar? El enigma de Sócrates se alza ante nosotros como una esfinge silente y cada uno de sus discípulos dibujó un retrato diferente.

Sin embargo, algo puede concederse a la obra artística de Platón, en la medida en que ésta escapa al dominio de su autor: hasta donde alcanza la evidencia textual, parece claro que para el propio discípulo la paradoja de Sócrates era difícilmente resoluble, y así se podría entender la veracidad que logra el personaje descrito en los primeros diálogos (tan opaco quizá, como lo somos unos a otros, e incluso a nosotros mismos, en el mundo externo al texto).

Éste es, pues, uno de los desacuerdos más importantes en los autores citados, la llamada "cuestión socrática». Pero no todo son desacuerdos, antes bien hay puntos en los que una gran parte de los estudiosos coinciden. Uno de esos puntos, relevantes para mi investigación, sería el de la gran diferencia entre la filosofía en la época clásica y toda la tradición posterior. Es en esos diálogos socráticos donde por última vez encontramos referencia a la cuestión de la vida buena en conexión con la determinación del objeto y método de la filosofía. ${ }^{23}$ La filosofía posterior, por el contrario, habría sido casi siempre una disciplina con aspiraciones eminentemente teóricas, sin apenas consecuencias en la vida cotidiana. ${ }^{24}$

Sin embargo, no todos entienden del mismo modo el papel del Sócrates platónico en ese contexto en que teoría y práctica se afectaban entre sí, y en última instancia, esta disparidad se refleja en la concepción que de la ironía presentan cada uno (la de Vlastos, a la que se enfrenta Nehamas, y la mía, como tercera en discordia).

Es justamente famoso el encomio, ya mencionado, de Alcibíades a Sócrates, legible en el Banquete de Platón, en el que, entre las muchas cosas en que Alcibíades incide, destaca quizá la caracterización de Sócrates en tanto que nuevo Marsias:

A Sócrates, señores, yo intentaré elogiarlo de la siguiente manera: por medio de imágenes. Quizás él creerá que es para provocar la risa, pero la ima-

\footnotetext{
23 Wolf, 2002, p. 48.

24 Nehamas, 2005, p. 11.
} 
gen tendrá por objeto la verdad, no la burla. Pues en mi opinión es lo más parecido a esos silenos existentes en los talleres de escultura, que fabrican los artesanos con siringas o flautas en la mano y que, cuando se abren en dos mitades, aparecen como estatuas de dioses en su interior ${ }^{25}$.

Ésta es la caracterización de Sócrates que asume como modelo Vlastos; más aún, la suya es una concepción de Sócrates en paralelo a la de un concepto en forma de antífrasis de la ironía. Debajo de la apariencia poco satisfactoria, en apariencia aporética, a menudo imitadora burlona del discurso de los sofistas, se ocultaría el verdadero sentido de la vida de Sócrates, su tarea vital universal. Asimismo, y en correspondencia con esto, las ironías empleadas por el Sócrates de los diálogos ocultarían un sentido recto que sería el inverso del aparente. Y para ello, el requisito central, sobre el que se articulan las disquisiciones de Vlastos, sería el de rechazar en todo momento la posibilidad de engaño y fraude en las palabras del Sócrates supuestamente real (frente a lo que venía siendo habitual en el contexto de la comedia ática antigua).

Sócrates, siempre según Vlastos, ${ }^{26}$ sería un predicador sin dogma, un profeta cuya doctrina sería la mencionada fe en que la "areté es conocimiento», pero que no actuaría como tal, sino que, haciendo honor a su carácter irónico, contradictorio, de paradoja viviente, ejercería su ministerio en las antípodas de un predicador, dedicándose a la refutación de sus interlocutores. Detrás de esta aparente contradicción, se ocultaría aquello que daría verdadero relieve a la figura del maestro de Platón, su carácter pedagógico, práctico y político, su altura moral.

Entre mentira e ignorancia, deberíamos escoger, según este autor, la ignorancia, pero no una completa sino parcial. Una ignorancia unida a un tipo de saber positivo sobre la moral, de un saber práctico que daría cuenta de las aseveraciones vistas a propósito del mal, el daño y el conocimiento ético. Una ironía engañosa, al estilo del modo de conducta del tipo teatral del eiron, ${ }^{27}$ ensom-

${ }^{25}$ Banquete, $215 \mathrm{~b}$.

26 Véase ahora, Vlastos, 1964.

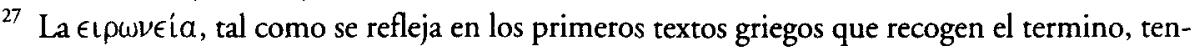
dría principalmente que ver con un modo de conducta ambiguo, con una actitud engañosa (Markantonatos, 1975 , p. 16). La palabra $\epsilon \iota \rho \omega \nu$ aparecería por primera vez en el contexto de la comedía ática antigua, exactamente en Las nubes de Aristófanes, ligada a un personaje, precisamente el de Sócrates, que se caracterizaba como un poco escrupuloso farsante (Aristófanes, 1995, p. 57). Y 
brecería el alcance ético del maestro socrático, desvelaría algún tipo de maldad en el hombre más justo de Atenas.

Pero, ¿cómo unir ignorancia y saber moral? Para dar cuenta de esta dificultad, recurre Vlastos a un imaginativo expediente, el de la ironía compleja. ${ }^{28}$ Este recurso consistiría en suma en negar verazmente, por un lado, tener conocimiento en ciertas cuestiones morales, en determinadas materias políticas, en saberes y decires abstractos, pero al tiempo guardando debajo de esta ignorancia, desde otra perspectiva, un saber completo. Yendo tras la verdad, tras la areté y la vida buena, el maestro dejaría que cada uno encontrase, mediante un examen de sí mismo que facilitaría el elenchos socrático, la verdad moral que ya guardaría en sí mismo, sin imponer la propia y dejando incluso que ésta fuese cuestionada. ${ }^{29}$ Ésta sería la forma del magisterio socrático, del Sócrates indagador, siempre abierto al reexamen de las diversas cuestiones tratadas en compañía de sus interlocutores.

En suma, tras la ignorancia y sin engaño alguno, se ocultaría la areté moral; en términos socráticos, el verdadero conocimiento. Es decir, que la figura de Sócrates no dibujaría otra cosa que la figura de la ironía entendida como antífrasis, esto es, diciendo lo contrario de lo que quiere dar a entender. Así, gracias a esta concepción de la ironía que una vez localizada se anula a sí misma, ${ }^{30}$ se podría escuchar la verdadera voz de Sócrates; en el silencio del texto hablaría el alma del autor, del personaje, del profeta.

Pero, ¿es ésta la única concepción posible de la ironía? Y, ¿resulta realmente satisfactorio lo que propone esta interpretación? Después de todo, si alguien ocul-

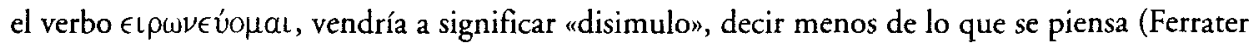
Mora, 1994, p. 1903). Pero, de todos modos, la etimología no es clara, ya que $\epsilon \iota \rho \omega \nu$ parece ser que tenía una relación mayor con nociones como la de "preguntar" o "querer decir algo" (Knox, 1961 , p. 3 y Mortara, 2000 , p. 190), aunque luego se haya asociado a la familia de palabras vinculadas con la impostura, el fraude, el engaño y, en general, a un tono ciertamente peyorativo.

${ }^{28}$ Vlastos, 1991, p. 13.

29 Otra cosa sería si esta concepción de la moral socrática, de su método, en la que el saber es condición necesaria y suficiente para la bondad moral, puede llegar a ser una plausible exigencia para una ética y dibujar una propuesta aceptable para nosotros.

${ }^{30}$ Pues, al localizar una ironía como tal, y a sabiendas de que su sentido recto es el inverso del aparente, la traducción sería inmediata y la ironía desaparecería. 
ta una verdad, de cuya convicción íntima nadie ha podido hacerle dudar, y trata de extender mediante una pedagogía revolucionaria esta verdad y este conocimiento, oculto tras el velo de la ignorancia, ¿acaso no cabría decir que ese es un dogmático encubierto?

Ésa es la respuesta que parece suscitar la ironía que no deja lugar a la ambigüedad, ya que ésta es la opción que, junto con el engaño, desecha el intérprete de un Sócrates moralista. Ésta es la ironía ridícula del maestro de escuela, la peligrosa voz de un dogmatismo encubierto. ${ }^{31}$ Y frente a ésta, la otra opción conocida, ligada a la concepción semántica alternativa de la ironía, la que perfila a un personaje enigmático, que quiere decir otras cosas, nada fáciles de determinar a veces, en lugar de las que da a entender (o mejor, en tensión con las que da a entender, ya que frente a la ironía simple, antifrástica, ésta amenaza con quedar siempre irresuelta, oscilante entre sentidos diversos ). ${ }^{32}$ En este último caso, nunca se estaría seguro de saber qué es lo que el irónico quería decir; simplemente inferiría que no es exactamente lo escuchado o leído, pero él nunca indicaría qué es lo que piensa en realidad, a qué se refiere.

Lo constitutivo de Sócrates y del concepto de ironía sería, pues, una distancia. Entre la sinceridad y una disimulación cercana al engańo, oscilando entre ellos, estaría el ocultamiento, que no engaña, pero que tampoco revela. ${ }^{33}$ En esa alternancia se asemejaría la ironía a la dialéctica y en su ser indiferente a la verdad y falsedad se alejaría de ella (o mejor, en su no saberse si es o no indiferente a la verdad). ${ }^{34}$ Más aun, incluso la forma del diálogo, su estructura última, en los primeros textos platónicos sería la de la ironía.

31 «Guárdese usted de la ironía que aquí se cultiva, ingeniero! ¡Guárdese en general de esa actitud del espíritu! Allí donde no sea una forma directa y clásica de retórica perfectamente inteligible para un espíritu sano, se convierte en una aberración, en un obstáculo para la civilización, en el vicio. (...)

"iMira, mira! — se dijo- Habla de ironía poco más o menos como habla de música. Ahora sólo falta que la califique de 'políticamente sospechosa' a partir del instante en que cesa de ser 'un medio de enseñanza directa y clásica'. Pero una ironía que 'no puede en ningún momento dar lugar al equívoco', ¿qué sería? Lo pregunto en nombre de Dios, puesto que yo también tengo derecho a la palabra. Eso es una ridiculez de 'maestro de escuela.' (Mann, 2004, pp. 304-305).

32 Nehamas, 2005, pp. 27ss.

33 Éste es el punto de vista de Nehamas a lo largo de todo su libro, tal y como lo expresa explicitamente en Nehamas, 2005, p. 100.

${ }^{34}$ Schaerer, 1941, pp. 192, 205. 
Pensemos en un diálogo platónico del primer período, como el Eutifrón, en el que el personaje es alguien prodigiosamente engreído, un $a \gamma a \zeta \omega$, el personaje que da título al diálogo, Eutifrón. Éste, que pretende ser sabio en las cosas de la religión, recibe una intensísima carga irónica por parte del $\epsilon \iota \rho \omega \nu$ sui generis que representa Sócrates. En este texto no hay personajes que ejerzan de espectadores, como en muchos otros diálogos, pero estamos nosotros, los lectores del texto, que siempre ocupamos las filas del fondo en el ágora o liceo ficticio que dibuja Platón. Tenemos pues algunos de los elementos que entran en muchas de las definiciones del concepto de ironía: un irónico, una víctima u objeto de la ironía y una audiencia, que entiende y no entiende al irónico, que es cómplice o víctima, de las implicaturas del orador, que comparte una misma comunidad discursiva que capta la regla que sigue el irónico, y tiene en cuenta los supuestos culturalmente compartidos o no. ${ }^{35}$

En este último punto se esboza el riesgo de la ironía, uno de sus peligros; después de todo, ¿quién me dice que he captado una ironía, que no se me ha pasado por alto algo, o que no he incurrido en una interpretación poco cuidadosa?

35 Irónico y víctima pueden ser la misma persona, asimismo el "público" o "audiencia» podría ser nocional, pero un cierto desdoblamiento, como enuncia claramente Schlegel, el "teórico" por excelencia de la ironía en el Romanticismo alemán, y más aún Baudelaire, una cierta reflexión, sí parece necesaria: "Sólo ella (la poesía trascendental) puede convertirse en un espejo de todo el mundo circundante, una imagen de la época. Y sin embargo, es ella la que puede también, la mayor parte de las veces, flotar entre lo representado y lo que lo representa, libre de todo interés real o ideal, sobre las alas de la reflexión poética y potenciar siempre de nuevo esta reflexión y multiplicarla como en una serie infinita de espejos", "Además, esta clase de poesía debe unir los materiales trascendentales en bruto y los preliminares de una teoría de la creatividad poética - que a menudo se encuentran en los poetas modernos- con la reflexión artística y la bella autorreflexión que están presentes en Píndaro (...)»( Schlegel, 1971, \$\$116, 238, la traducción es mía). «En lo cómico absoluto y en lo significativo existe la idea dominante de superioridad; que para que exista lo cómico (...) es necesaria la presencia de dos seres (...) hay que hacer una excepción con las personas que han convertido en un oficio el desarrollo en sí mismos del sentimiento de lo cómico y que lo sacan también de sí mismos para diversión de sus prójimos, fenómeno que forma parte de todos aquellos hechos artísticos que denotan en el ser humano la existencia de una permanente dualidad, la posibilidad de ser a la vez uno mismo y otro" (Baudelaire, 2000, pp. 1253-1254).

Además, en el caso de la ironía pragmática, la referencia social, la estructura de proceso comunicativo, son ineludibles. Los casos límite, como el de la ironía amarga o privada, podrían acercarse más a una concepción semántica o tocar, en el límite, con otros conceptos como el del cinismo. Asimismo, la referencia a una audiencia, victima e irónico, como estamos viendo y ahora discutiré, no excluyen una concepción semántica. 
La ironía, esto es, parte de su lado amenazante, puede volverse contra quien la ejerce o contra quienes creían estar del lado del irónico. Pensemos de nuevo en Eutifrón, el de recto comprender: acaba abandonando precipitadamente la conversación con Sócrates y parece no haber sido afectado por el maestro de Platón, sí turbado; pero la ceguera, respecto de su propia ignorancia, al final del diálogo no habría desaparecido. Aunque, ¿acaso nosotros reaccionamos de modo diferente a Eutifrón? No, en poco o en nada nos afecta; no nos lleva a cambiar vida la lectura de los diálogos platónicos. Pero entonces, ¿porqué creemos estar del lado del irónico Sócrates y no haber sido envueltos por la ironía del autor de los diálogos, Platón? Éste, sentado en la última fila del ágora nos observaría sonriendo, ya que las ironías quizá se dirijan en última instancia al lector. Pero, posiblemente, no duraría mucho su sonrisa puesto que esa posibilidad, finalmente, también se dirige al propio Platón, ya que, como dijimos en los inicios de este artículo, Sócrates es una paradoja cuyo sentido se le podría haber escapado también al autor de los diálogos.

\section{III}

Es cierto que Sócrates no dejó nada escrito, y que jamás argumenta, ni demuestra nada, ni tendría razones, o al menos no las esgrime, para convencer a nadie de las bondades de su arte de vivir. Asimismo, el que él viva una vida buena, con areté, parece contradictorio con su pretendida ignorancia. Sin embargo, cabe preguntarse si, por eso mismo, deberíamos abandonar en la incertidumbre su magisterio, como un constante deslizarse entre alternativas diversas, en tensión, como un reflejo de su concepción de la ironía, tal como la interpreta Nehamas. No lo creo y cabe para ello esgrimir el testimonio de un autor poco valorado en nuestros días como retratista de Sócrates, Jenofonte. ${ }^{36}$

En una ocasión, según nos cuenta Jenofonte, ${ }^{37}$ el sofista Hipias acusó a Sócrates de hacer preguntas sobre las virtudes, pero sin ofrecer nunca sus respuestas.

36 Aunque ésta no es una posición compartida por todos los autores relevantes y, por ejemplo, en Nietzsche, pueden encontrarse aseveraciones que vendrían a afirmar mi propia interpretación: «El libro más atractivo de la literatura griega: Memorabilia Socratis» (Nietzsche, 1996, p. 306, fragmento de 1879, debo la referencia a David Mateu Alonso).

37 Memorabilia 4, 4, 10-11, tomo la cita de Nehamas, pero para criticar su interpretación de Sócrates. 
Y éste le respondió, de un modo en principio sorprendente, que él siempre estaba "demostrando" su propia concepción de la justicia. Al pedirle Hipias que definiese lo que es la justicia, le respondió que su demostración consistía en que él nunca actuaba injustamente, y que sus acciones eran una evidencia mucho más seria que sus palabras.

Como decía cierto filósofo, si quieres saber si alguien es un santo, no le pidas una demostración, un argumento ligado a un paradigma de racionalidad científica, una demostración lógico-deductiva, pídele que te muestre su vida. La filosofía, la ética, el magisterio socrático podrían ser una cuestión más mostrativa que demostrativa. El saber de la areté no sería un saber técnico, ${ }^{38}$ de la techne, que consistiría en un saber de los medios adecuados para alcanzar metas determinadas, y que nada se plantearía sobre éstas, esto es, un saber éticamente neutral, sino que sería una pregunta por estas metas. Este saber recurriría al elenchos para ordenar el antes desordenado campo de las opiniones y conceptos, por medio de los cuales nos referimos a la vida buena, y sería un saber siempre refutable. Es más, de hecho el elenchos es eminentemente negativo, pero también podría asentarse si resistiese el embate del "método" socrático de las preguntas irónicas (como sucede con la afirmación del Oráculo relativa a la sabiduría de Sócrates, que resiste todos sus intentos de refutación).

La ironía no ocultaría una verdad dogmática tras de las apariencias, pero tampoco sería un mero ocultarse. A lo que apuntaría en la polis, su función en ella, sería a cómo no deben ser las cosas, a qué es lo que no encaja en una comunidad de discurso, en la ciudad, en relación con las normas de discurso, con la forma de vida, de ese grupo. La corrección moral, el filo evaluativo de la ironía, estaría inscrito en el proceso de comunicación, en la praxis, y trataría de testar esas mismas normas o mostrar otras posibles. La ironía de Sócrates como forma de vida no se defiende con argumentos de tipo lógico-deductivos, pero tampoco queda en la mera proposición, ni en la persuasión, esto es, en una suerte de proceder irracional. Antes bien, a mi juicio, la propuesta socrática descansaría en una concepción amplia de racionalidad, en el mostrar cómo un modo de vida puede contribuir a enriquecer el nuestro, o en mostrar cómo estamos en contradicción con aquel en el que nos encontramos. Se trataría en realidad de dejar que cada uno,

${ }^{38}$ Aquí sigo a Wolf y a Nehamas (Wolf, 2002, p. 52; Nehamas, 2005, p. 121). 
en base a esas preguntas y sus respuestas, tuviera en cuenta estas consideraciones a la hora de cambiar su vida, de fundamentar sus preferencias, de reintegrarse en su comunidad discursiva. Y la propuesta socrática sería además, puede desprenderse de lo dicho, una propuesta social, para la polis, y no sólo un proyecto personal, para el cuidado de sí. ${ }^{39}$

Éstas serían algunas de las lecturas, entre ellas la mía, acerca de la figura de Sócrates, de su contribución al concepto de ironía. Pero no serían las únicas, ni las más relevantes, históricamente. De hecho, para la historia de la ironía, y tras el largo sueño retórico de siglos que imperó después de Aristóteles, la figura de Sócrates redivivo sería fundamental. El siguiente momento álgido de la ironía, ya en el siglo XVIII y en el seno del primer Romanticismo alemán, giraría en parte en torno al eje de la figura socrática. De la interpretación de su figura, de la comprensión de la ironía antigua, de la ironía del maestro de Platón, depende gran parte de la concepción romántica, moderna, de la ironía. De la disputa en torno a su figura surgen una serie de rasgos que contribuyen a iluminar, y a aumentar, la pléyade de sentidos que constituyen el concepto de ironía y la propia caracterización de ésta tal como he tratado de exponer y discutir en esta pequeña meditación socrática, siendo la central, a mi juicio, aquella en que la ironía se muestra desde su lado más pragmático como una forma de vida.

\section{BIBLIOGRAFÍA}

Aristofanes, Las nubes. Las ranas. Pluto, trad. Francisco Rodríguez Adrados y Juan Rodríguez Somolinos, Cátedra, Madrid, 1995.

39 Aquí me enfrento a lo que asevera Nehamas y una gran parte de la tradición más importante de exegetas de Sócrates, destacando entre los clásicos Hegel y Kierkegaard. Sigo aquí muy parcialmente la lectura de Marzoa (Martínez Marzoa, 2005, pp. 24, 36, 53), quien hilvana en torno a la distancia diversos elementos: la fundación de la ciudad, la comedia ática antigua y la figura de Sócrates y, sin saberlo, en suma, esboza la forma de la ironía y dota a ésta de una serie de referencias al poder, a lo social en suma, que han ido apuntando a lo largo de mi ensayo (la referencia central respecto a la distancia en la comedía, por ejemplo, es la de la parábasis, figura teatral central en la historia de nuestro concepto, ya que mediante ella define el ya mencionado Schlegel la ironía). Y añadiré, además, mis consideraciones sobre la concepción pragmática de la ironía, que avalan el contexto comunicativo del fenómeno. 
Baudelaire, Charles, Poesia Completa. Escritos autobiográficos. Los Paraísos artificiales. Crítica artística, literaria y musical, trad. Javier del Prado y José A. Millán, Espasa Calpe, Madrid, 2000, pp. 1233-1254.

DE MAN, Paul, El concepto de ironia, trad. Manuel Asensi, Episteme, Valencia, 1996.

Ferrater Mora, José, "Ironía” en José Ferrater Mora, Diccionario de Filosofía vol. II, Ariel, Barcelona, 1994, pp. 1903-1905.

HEGEL, Georg Wilhelm Friedrich, Lecciones sobre la historia de la filosofia vols. I, II y III, trad. Wenceslao Roces, FCE, México, 1955.

Knox, Norman D., The Word Irony and its Context, Duke U. P., Durham y Carolina del Norte, 1961.

KoselleCK, Reinhart, Futuro pasado. Para una semántica de los tiempos históricos, trad. Norberto Smilg, Paidós, Barcelona, 1993.

MANn, Thomas, La montaña mágica, trad. Mario Verdaguer, Edhasa, Barcelona, 2004.

Markantonatos, G., "On the Origin and Meanings of the Word eirôneia», Rivista di filologia e d'istruzione classica, núm. 103, 1975, pp. 16-21.

MARRADES, Julián, "Comprensión del sentido y normas de racionalidad. Una defensa de Peter Winch», Critica, Revista Hispanoamericana de Filosofia, vol. 30, núm. 89, 1998, pp. 45-93.

Martínez Marzon, Felipe, El saber de la comedia, A. Machado Libros, Madrid, 2005.

Montaigne, Michel de, Ensayos vol. III, trad. Dolores Picazo y Almudena Montojo, Cátedra, Madrid, 1987.

Mortara, Bice, Manual de retórica, trad. María José Vega, Cátedra, Madrid, 2000.

Nehamas, Alexander, El arte de vivir. Reflexiones socráticas de Platón a Foucault, trad. Jorge Brioso, Pre-Textos, Valencia, 2005.

NiETZSCHE, Friedrich, La genealogía de la moral: un escrito polémico, trad. Andrés Sánchez Pascual, Alianza, Madrid, 1997.

NIETZSCHE, Friedrich, Humano demasiado humano, trad. Alfredo Brotons, Akal, Madrid, 1996.

PeñalVer, Patricio, «Breve tentativa de restituir la ipsimissima vox de Sócrates», Actas Congreso de la SAF, Santiago de Compostela, 2005.

Platón, Diálogos, trad. de VV. AA., Gredos, Madrid, 1981-1989. 
QUINTILIANO, Institutio oratoria, CSIC, Madrid, 1947.

SCHAERER, René, "Le mécanisme de l'ironie dans ses rapports avec la dialectique", Revue de métaphysique et de morale, núm. 48, 1941, pp. 181-209.

SCHLEGEL, Friedrich, Friedrich Schlegel's "Lucinde" and the Fragments, trad. Peter Firchow, University of Minnesota Press, Minneapolis, 1971.

VLASTOS, Gregory, Socrates, Ironist and Moral Philosopher, Cornell U. P., Ithaca y New York, 1991.

VLASTOS, Gregory, «La paradoja de Sócrates», Revista de Occidente, núm. 11, 1964, pp. 129-157.

WitTGENSTEIN, Ludwig, Investigacions filosòfiques, trad. Josep M. Terricabras, Edicions 62, Barcelona, 1997.

Wolf, Ursula, La filosofia y la cuestión de la vida buena, trad. Ángel Galán, Síntesis, Madrid, 2002. 